\title{
Science Communication, Strategic Communication and Rhetoric: \\ The Case of Health Authorities, Vaccine Hesitancy, Trust and Credibility ${ }^{1}$
}

\begin{abstract}
There is a great potential in pulling together science communication and strategic communication, especially given how the former has gained importance in organizational contexts. Strategic communication, including rhetorical theory, can offer insights that are invaluable to understand the contests over what "truth" is and how different political perspectives influence such debates. The case of vaccine hesitancy is used as an illustration of the challenges posed to organizations and organizational communication around science-related issues today. There is a need to understand the audience in order to build credibility, or ethos, while at the same time recognizing the contingent and situational character of this endeavor.
\end{abstract}

The concluding chapter of the Oxford Handbook of the Science of Science

Communication highlights some of the challenges facing science communication, among these, a "political environment filled with partisans eager to challenge the validity of ideologically inconvenient science" (Scheufele, Jamieson, \& Kahan, 2017, p. 1). In this regard, some scholars and commentators have used the moniker of a "post truth"-era (e.g., Mcintyre, 2018). By this, they basically mean that anything goes. If you feel that scientific evidence on an issue is not true, that is your truth and you are indeed entitled to it. Exhibit A in this regard has been how conclusions from the vast research on climate change are challenged (e.g., Groves, 2019). Furthermore, science communication is likely to "encounter questions about religion, morality, and ethics that do not have scientific answers" (Scheufele et al., 2017, p. 9). The editors, of the Handbook conclude, nonetheless, that the scientific community as such has not experienced declining trust.

\section{The case of vaccine hesitancy}

While science in general might hold its ground, there are alarming figures concerning some issues where science has been more or less united - for instance the need to vaccinate against influenza and measles. Research has concluded that public trust in vaccines and immunization has declined (e.g., Yaqub, Castle-Clarke, Sevdalis, \& Chataway, 2014). This, in turn, can have grave consequences, as stated by the World Health Organization (WHO): "Each year, across the globe, there are an estimated 1 billion cases of influenza, 3-5 million are severe

${ }^{1}$ PREPRINT OF Ihlen, Ø. (2020). Science communication, strategic communication and rhetoric: the case of health authorities, vaccine hesitancy, trust and credibility. Journal of Communication Management, 24(3), 163167. doi:10.1108/JCOM-03-2020-0017 
cases, and 290 000-650 000 lead to influenza-related respiratory deaths" (World Health Organization [WHO], 2019, p. 2). Concerning measles, the number of reported cases $(1,250)$ in the United States has increased 336 \% from 2018 and 1,984\% since 2010 (Center for Disease Control and Prevention, 2019). In the period September 2018-August 2019, 13,264 cases of measles were reported by the 30 European Union/European Economic Area (EU/EEA) member states (European Centre for Disease Prevention and Control, 2019, October). Vaccine hesitancy plays a major role in this picture and has emerged as a main issue for public health and public relations/information communicators (e.g., Larson, Cooper, Eskola, Katz, \& Ratzan, 2011). WHO (2019) has stated that vaccine hesitancy is a key barrier for overcoming epidemic/pandemic outbreaks of influenza, measles and other vaccine-preventable diseases. Numerous studies have analyzed the drivers of vaccine hesitancy. Most of these are related either to complacency, convenience or confidence (MacDonald \& Sage Working Group on Vaccine Hesitancy, 2015). The latter term is defined as:

... trust in (i) the effectiveness and safety of vaccines; (ii) the system that delivers them, including the reliability and competence of the health services and health professionals and (iii) the motivations of policy-makers who decide on the needed vaccines. (MacDonald \& Sage Working Group on Vaccine Hesitancy, 2015, p. 4162)

In other words, drivers for vaccine hesitancy are linked to the success or lack of success in the communication of science. This is a trust building exercise that is initiated in an organizational context with actors such as the World Health Organization (WHO), national health authorities and services, NGOs, social movements, and so forth.

Scholarly attention has also been dedicated to vaccine hesitancy and communication, but mostly without consulting the theory of strategic communication or rhetoric (e.g., Thomson, Vallee-Tourangeau, \& Suggs, 2018). While communication alone is not going to stop distrust or dissent (Larson et al., 2011), it has, nonetheless, been singled out as having a key role (World Health Organization [WHO], 2019, p. 2 and 10). Communication should "instill public confidence and uptake" [emphasis added] and "[e]ffective communication strategies are important to engage policy-makers and communities in prevention and control efforts, and to increase buy-in and confidence" [emphasis added] (World Health Organization [WHO], 2019, p. 2 and 10).

Research on strategic communication has demonstrated that confidence hinges on the 
credibility or trustworthiness of the communicator. Social actors appear to be credible or trustworthy based on perceptions of such aspects as competence, expertise, knowledge, objectivity, fairness, consistency, sincerity, caring, empathy, compassion and goodwill (Covello, 2009; Renn \& Levine, 1990). The existing body of knowledge on vaccine communication could be usefully supplemented with insights on such matters culled from studies of strategic communication, broadly defined here to include rhetorical theory. Public health authorities need to understand audience perceptions in order to strengthen credibility, while recognizing the contingent and situational character of this endeavor. This, however, is a challenge that has to be tackled by all kinds of organizations and hence is relevant for all types of organizational communication.

\section{Strategic communication, rhetorical theory and the audience}

Strategic communication can be defined as "the purposeful use of communication by an organization or other entity to engage in conversations of strategic significance to its goals" (Zerfass, Verčič, Nothhaft, \& Werder, 2018, p. 493). This understanding sees strategic communication as an umbrella term, whereby insights from other disciplines can be usefully integrated. I argue that theory from rhetoric (e.g., Cockcroft \& Cockcroft, 2014) and specifically organizational rhetoric (Ihlen \& Heath, 2018) is helpful to understand organizational discourse, its effects, as well as its role in society. Rhetoric offers practical advice for organizations for how to reach their goals, but also incorporates epistemological perspectives countering naive realism and platonic notions of absolute truth (Vickers, 1988/1999). Rhetoric alerts us to how knowledge is generated and socially constructed through communication.

In strategic communication and rhetorical theory, there is a clear emphasis on the need to understand the audience or target group before trying to communicate (e.g., Edwards, 2018; Johnston \& Taylor, 2018). It is simply not possible to persuade anyone if you are not able to, somehow, make a connection with what they believe to be true or with some of their values. Furthermore, the audience is actively shaping the meaning of messages, which has led rhetorical scholars to talk about "zones of meaning" (Heath, 1993). Stakeholders might have a whole range of different interpretations, thus leading to the proposition that meaning is co-defined and cocreated.

Research on vaccine hesitancy has introduced a continuum ranging from full acceptance to outright refusal of all vaccines (MacDonald \& Sage Working Group on Vaccine Hesitancy, 
2015). Major reasons for hesitancy include, for instance, "[d]istrust of government sources, perceived low severity of illness, perceived ineffectiveness of vaccine, fear of needles/pain of vaccination, perceived low risk of contracting illness, and mainly, fear of side effects and vaccine safety" (Yaqub et al., 2014, p. 4). If a communication strategy is to succeed, communicators need to understand such predispositions and the values of the audience. In climate change communication, communicators are urged to relate to people's different ethical, ideological, political beliefs that lead to different historical interpretations and competing visions for the future (Hulme, 2009).

Therefore, the key take-away point is that the information deficit theory does not hold as a single factor explanation (see also the debate within science communication, e.g., Bucchi \& Trench, 2016). Vaccine hesitancy is not necessarily based on lack of information. Instead, issues

of mistrust show up more frequently (Yaqub et al., 2014). Hence, efforts to strengthen credibility becomes crucial. The literature on vaccine communication emphasizes, for instance, the need to understand the audience, to target their needs, to engage in dialogue (e.g., Thomson et al., 2018). The literature does not, however, really engage with the specifics of how you construct strategies to come across as trustworthy. Here strategic communication and more specifically rhetorical theory have useful insights.

\section{The trustworthiness of the communicator}

Health authorities that want to communicate about the science of vaccines can pull on ancient and modern-day insights from theories on strategic communication, persuasion and rhetorical writing on credibility or ethos. Ethos can be defined as "character as it emerges in language" (Baumlin, 2001, p. 263). However, character cannot emerge without an audience, which in turn has certain predispositions and values they adhere to, and against which the speaker is measured. In other words, through language, the rhetor is attempting to trigger the "audience's projection of authority and trustworthiness onto" him or herself (Baumlin \& Baumlin, 1994, p. 99). In his treaty on rhetoric, Aristotle (trans. 2007) devised that rhetors should demonstrate practical wisdom, virtue and good will to strengthen ethos. In turn, such individual level traits can also influence perceptions of institutional characteristics, thus leading to institutionally or organizationally based trust towards an institution and/or its representatives (Baumlin \& Scisco, 2018).

It is, however, necessary to keep in mind that there are at least two contrasting 
epistemological poles that are important in this regard - the realist Platonic position focusing on the expected, and the situational perspective, that which "resists method" (Miller, 2002, p. xiii). Given the contingent character of rhetoric, a mode of improvisation is devised for rhetors. The rhetor "must carry a flexible attitude into any given rhetorical situation" (p. 9). Thus, ethosbuilding has to rely on dynamic principles and shun narrowly fixed rules. The endeavor is made even more complicated by how the rhetorical situations of today are more fluid and difficult to demarcate (Edbauer, 2005). Utterances meant for one audience in a particular situation, can live on in social media where other audiences pile on comments without taking the original setting into context. The literature on rhetoric expands on this and other aspects concerning how credibility is strengthened.

\section{Conclusion}

As stated in the abovementioned Oxford Handbook of the Science of Science Communication, we need empirical research to understand how to best communicate about science (Scheufele et al., 2017). The advent of this special issue on Communicating Science in Organizational Contexts is a good step in such a direction. Good empirical research is of course reliant on good theoretical frameworks, which in turn are likely to benefit from insights pulled from across siloed disciplines. Opening up for a meeting between science communication, strategic communication of organizations and rhetoric is one possible route to take. In this short commentary I have pointed to one of the major contributions the latter disciplines could offer to science communication, namely providing the essential knowledge to strengthen credibility. While much attention has been geared towards understanding the audience, strategic communication and rhetoric in particular goes further and also spells out the strategic implications for communication that is intended to strengthen credibility. Additionally, rhetoric alerts us to how credibility, or ethos, is not a fixed quality in a sender or a text but is situational and constantly negotiated. While the case of vaccine hesitancy and health authorities is used as an illustration, all organizations share the need to somehow have others believe in what they are saying. The toolboxes of strategic communication and rhetoric holds a number of insights and approaches that could benefit science communication.

\section{References}


Aristotle. (trans. 2007). On rhetoric: A theory of civic discourse (G. A. Kennedy, Trans. 2 ed.). New York, NY: Oxford University Press.

Baumlin, J. S. (2001). Ethos. In T. O. Sloane (Ed.), Encylopedia of rhetoric (pp. 263-277). Oxford University Press: New York.

Baumlin, J. S., \& Baumlin, T. F. (1994). On the psychology of the pisteis: Mapping the terrains of mind and rhetoric. In J. S. Baumlin \& T. F. Baumlin (Eds.), Ethos: New essays in rhetorical and critical theory (pp. 91-112). Dallas, TX: Southern Methodist University Press.

Baumlin, J. S., \& Scisco, P. L. (2018). Ethos and its constitutive role in organizational rhetoric. In Ø. Ihlen \& R. L. Heath (Eds.), Handbook of organizational rhetoric and communication (pp. 201-213). Malden, MA: Wiley Blackwell.

Bucchi, M., \& Trench, B. (2016). Science communication and science in society: A conceptual review in ten keywords. Tecnoscienza (Italian Journal of Science \& Technology Studies), 7(2), 151-168.

Center for Disease Control and Prevention. (2019). Measles cases and outbreaks. Retrieved from https://www.cdc.gov/measles/cases-outbreaks.html

Cockcroft, R., \& Cockcroft, S. (2014). Persuading people: An introduction to rhetoric (3 ed.): Palgrave Macmillan.

Covello, V. T. (2009). Strategies for overcoming challenges to effective risk communication. In R. L. Heath \& D. O'Hair (Eds.), Handbook of risk and crisis communication (pp. 143-167). New York, NY: Routledge.

Edbauer, J. (2005). Unframing models of public distribution: From rhetorical situation to rhetorical ecologies. Rhetoric Society Quarterly, 35(4), 5-24.

Edwards, H. H. (2018). Conceptualizing audience in the communication process. In Ø. Ihlen \& R. L. Heath (Eds.), Handbook of organizational rhetoric and communication (pp. 373-382). Malden, MA: Wiley Blackwell.

European Centre for Disease Prevention and Control. (2019, October). Monthly measles and rubella monitoring report.

Groves, C. (2019). Post - truth and anthropogenic climate change: Asking the right questions. Wiley Interdisciplinary Reviews: Climate Change, 10(6), e620.

Heath, R. L. (1993). Toward a paradigm for the study and practice of public relations: A rhetorical approach to zones of meaning and organizational prerogative. Public Relations Review, 19(2), 141-155.

Hulme, M. (2009). Why we disagree about climate change: Understanding controversy, inaction and opportunity. New York, NY: Cambridge University Press.

Ihlen, Ø., \& Heath, R. L. (Eds.). (2018). Handbook of organizational rhetoric and communication. Malden, MA: Wiley Blackwell.

Johnston, K. A., \& Taylor, M. (Eds.). (2018). Handbook of communication engagement. Malden, MA: Wiley Blackwell.

Larson, H. J., Cooper, L. Z., Eskola, J., Katz, S. L., \& Ratzan, S. (2011). Addressing the vaccine confidence gap. The Lancet, 378(9790), 526-535. doi:10.1016/s0140-6736(11)60678-8

MacDonald, N. E., \& Sage Working Group on Vaccine Hesitancy. (2015). Vaccine hesitancy: Definition, scope and determinants. Vaccine, 33(34), 4161-4164. doi:10.1016/j.vaccine.2015.04.036

Mcintyre, L. (2018). Post-truth. Cambridge, MA: MIT Press.

Miller, C. R. (2002). Foreword. In P. Sipiora \& J. S. Baumlin (Eds.), Rhetoric and kairos: Essays in history, theory, and praxis (pp. xi-xiii). Albany, NY: State University of New York Press.

Renn, O., \& Levine, D. (1990). Credibility and trust in risk communication. In R. E. Kasperson \& P. J. Stallen (Eds.), Communicating risk to the public (pp. 175-218). Dordrecht, Germany: Springer.

Scheufele, D. A., Jamieson, K. H., \& Kahan, D. (2017). Conclusion-On the horizon: The changing science communication environment. In K. H. Jamieson, D. Kahan, \& D. A. Scheufele (Eds.), The Oxford Handbook of the Science of Science Communication (pp. 461).

Thomson, A., Vallee-Tourangeau, G., \& Suggs, L. S. (2018). Strategies to increase vaccine acceptance and uptake: From behavioral insights to context-specific, culturally-appropriate, evidence-based communications and interventions. Vaccine, 36(44), 6457-6458. doi:10.1016/j.vaccine.2018.08.031

Vickers, B. (1988/1999). In defence of rhetoric. Oxford: Clarendon Press.

World Health Organization [WHO]. (2019). Global Influenza Strategy for 2019-2030. Geneva, Switzerland: WHO.

Yaqub, O., Castle-Clarke, S., Sevdalis, N., \& Chataway, J. (2014). Attitudes to vaccination: a critical review. Social Science Medicine, 112, 1-11. doi:10.1016/j.socscimed.2014.04.018

Zerfass, A., Verčič, D., Nothhaft, H., \& Werder, K. P. (2018). Strategic communication: Defining the field and its contribution to research and practice. International Journal of Strategic Communication, 12(4), 487-505. doi:10.1080/1553118X.2018.1493485 